\title{
Biofilms in Shower Hoses
}

3 Caitlin R. Proctor ${ }^{1,2}$, Mauro Reimann ${ }^{2}$, Bas Vriens ${ }^{3}$, Frederik Hammes ${ }^{1}$

4

$5{ }^{1}$ Department of Environmental Microbiology, Eawag, Swiss Federal Institute of Aquatic Science 6 and Technology, Dübendorf, Switzerland

$7{ }^{2}$ Department of Environmental Systems Science, Institute of Biogeochemistry and Pollutant Dy8 namics, ETH Zürich, Zürich, Switzerland

$9 \quad{ }^{3}$ Department of Water Resources and Drinking Water, Eawag, Swiss Federal Institute of Aquatic 10 Science and Technology, Dübendorf, Switzerland

* Corresponding author:

24 Name: Frederik Hammes

$25 \quad$ Tel.: $\quad+41587655372$

$26 \quad$ Fax.: $\quad+41587655802$

27 Email: frederik.hammes@eawag.ch

28 This document is the accepted manuscript version of the following article:

Proctor, C. R., Reimann, M., Vriens, B., \& Hammes, F. (2018). Biofilms in shower hoses. water Research, 131, 274-286. https://doi.org/10.1016/j.watres.2017.12.027 
Shower hoses offer an excellent bacterial growth environment in close proximity to a critical enduser exposure route within building plumbing. In a global survey, biofilms from 78 shower hoses from 11 countries were characterized in terms of cell concentration $\left(4.1 \times 10^{4}-5.8 \times 10^{8} \mathrm{cells} / \mathrm{cm}^{2}\right)$, metals accumulation (including iron, lead, and copper), and microbiome composition (including presence of potential opportunistic pathogens). In countries using disinfectant, biofilms had on average lower cell concentrations and diversity. Metals accumulation (up to $5 \mu \mathrm{g}-\mathrm{Fe} / \mathrm{cm}^{2}, 75 \mathrm{ng}$ $\mathrm{Pb} / \mathrm{cm}^{2}$, and $460 \mathrm{ng}-\mathrm{Cu} / \mathrm{cm}^{2}$ ) seemed to be partially responsible for discoloration in biofilms, and likely originated from other pipes in the building. While some potential opportunistic pathogen genera (Legionella) had positive correlations with biofilm cell concentration, others (Mycobacterium, Pseudomonas) had surprisingly non-existent or negative correlations with biofilm cell concentrations. In a follow-up study, 15 identical shower hoses were installed for the same time period in the same country, and both stagnant and flowing water samples were collected. Ecological theory of drift and selection helped to explain microbiome composition and diversity differences between biofilm, stagnant and flowing water samples. Shower hose age helped to explain metals accumulation but not biofilm cell concentration, while frequency of use may influence biofilm cell concentration. Given the uncontrolled nature of showers in real homes, more controlled tests are necessary to disentangle individual drivers of biofilm growth in this unique environment. However, given the detection of potential opportunistic pathogens (e.g. L. pneumophila in 21/78 shower hoses), shower hose biofilms are clearly a critical element of building plumbing, and a potential target for building plumbing monitoring.

Keywords: shower hose; building plumbing; biofilm 


\section{Introduction}

Showers have been implicated as a route of infection for opportunistic pathogens (Schoen and Ashbolt, 2011). However, surprisingly little research attention has been paid to these final meters of water distribution, i.e., shower heads (Feazel et al., 2009) and shower hoses (Collins et al., 2017; Proctor et al., 2016; Soto-Giron et al., 2016). Within the building plumbing context, shower hoses are uniquely exposed to a triple threat of exacerbated bacterial growth factors. (1) They are typically exposed to warm water (rather than only cold or hot water), and would be subject to distal end cooling, even if used with properly regulated and controlled hot water recirculation systems (Rhoads et al., 2016). (2) They typically have long stagnation intervals: in a study including more than 700 homes with 2.6 persons/household, showers were used for 1.8 showers/day with 7.8 minutes/shower on average (i.e., stagnant 23.8 hours/day) (DeOreo et al., 2016). (3) The interior hose is made from flexible polymeric materials that leach significant amounts of biodegradable organic carbon; considerably more than hard pipe materials used otherwise in building plumbing (Bucheli-Witschel et al., 2012; Proctor et al., 2016).

Excessive bacterial growth in the last meters before consumer exposure during showers presents a potential health risk. Opportunistic pathogens, including Legionella pneumophila, Mycobacterium (Table S1). Interest in building plumbing opportunistic pathogen management is increasing slowly. For example, regulations in Germany require periodic L. pneumophila testing in homes when water boilers 
exceed $400 \mathrm{~L}$ in size (BMJV, 2011), and new Swiss legislation requires testing of shower water in public buildings (EDI, 2016). However, these monitoring activities are extremely laborious and the regulations often fall short both in terms of sampling methods (Wang et al., 2017) and preventative actions. For example, although materials in drinking water household plumbing are typically quality-controlled to some extent (e.g. (CEN, 2013)), the materials used specifically in shower plumbing are often completely unregulated because shower water is not necessarily considered as 'potable water' (BVer LMG, 2017). Moreover, while other pipe materials are installed by qualified professionals, shower hoses remain one of few components of water distribution that can be replaced by the consumers themselves. Consumers' choice in replacement hoses is driven only by functionality and aesthetics, with ignorance concerning potential health impacts. This is especially concerning because shower hoses are literally the last meter before water reaches the end-user, and are often used to more easily bathe patients and the elderly whom are at higher risk for opportunistic pathogen infection.

The unique bacterial growth environment and potential relevance to human health necessitate a better understanding of the biofilms that develop in shower hoses in the final meters of water distribution. The first goal of this study was a detailed characterization of biofilms in shower hoses collected from around the world, looking at biofilm concentrations of bacteria and metals, microbiome composition, and the presence of opportunistic pathogens. In addition to this global survey, a follow-up study was conducted to further identify important factors in biofilm formation and to determine biofilms' relationship to the water phase. 


\subsection{Sample collection}

Global survey: Shower hoses were collected from 78 showers across 11 countries on 3 continents

(Belgium, Denmark, Germany, Latvia, Portugal, Serbia, South Africa, Spain, the United Kingdom

(UK), and the United States (US)). Volunteers were instructed to detach the shower hose from all

fittings and to gently decant water from the hose. Hoses were sealed with autoclaved $1 / 2$ inch stoppers and stored in a plastic bag for transport to the lab within one week of removal. All volunteers also completed a brief survey to ascertain age (time since hose installation) and general water qualities (i.e., chlorination).

All samples were processed within one day of arrival to the laboratory. The outer casing was removed and the flexible plastic hose was cut into sections for analysis. Two 5-cm sections from either end were stored in Greiner tubes with $0.2 \mu \mathrm{m}$ filtered mineral water (Evian, France) for biofilm visualization. A $90-\mathrm{cm}$ section was used for biofilm extraction, and the remainder was discarded. The $90-\mathrm{cm}$ section was filled with $20 \mathrm{~mL}$ sterile glass beads ( $3 \mathrm{~mm}$ diameter) and filtered mineral water. All sections were stored at $4{ }^{\circ} \mathrm{C}$ in the dark until analysis.

Follow-up study: A follow-up study was conducted for 15 showers in Switzerland. All participants were given the same type of PVC-P shower hose to use for 1.5 years. Hoses and more detailed information on use patterns were collected as described above. To determine the biofilms' relationship to the water phase, three $1 \mathrm{~L}$ water samples were taken from each home: (1) stagnant from the shower hose after overnight stagnation (exact stagnation duration unknown), (2) warm flowing - from the shower hose after five minutes of flushing with warm water (i.e., showering temperature, $35-45^{\circ} \mathrm{C}$ ), and (3) cold flowing - from the nearest tap after five minutes of flushing with cold water (i.e., distribution system water without shower hose influence).

\subsection{Biofilm visualization}

Biofilm structure and thickness were characterized with optical coherence tomography (OCT), using a Spectral Domain OCT Imaging System (930nm, OCT System Ganymede, Thorlabs GmbH, 
croscopy and Image Analysis (University of Zurich) on $1 \mathrm{~cm}^{2}$ pieces that were fixed with $2.5 \%$ Glutaraldehyde and stored at $4^{\circ} \mathrm{C}$ in the dark.

\subsection{Biofilm extraction}

Biofilm was extracted using a repeated sonication strategy similar to (Proctor et al., 2016). The 90$\mathrm{cm}$ section with glass beads and filtered mineral water was inverted five times and then sonicated in a bath (Bandelin Sonorex, Rangendingen, Germany) for five minutes. The water was collected and replaced with new filtered mineral water. In total, five rounds of sonication and replacement were completed for each hose. After the final step, beads were removed and discarded, and hoses were filled with only filtered mineral water for a final rinsing step. The total biofilm suspension was sonicated with a needle (Sonoplus HD 2200, Bandelin Sonrex, Rangendingen, Germany) for 30 seconds for homogenization and was aliquoted for further analysis.

\subsection{Flow cytometry (FCM)}

Staining and FCM analysis was done as described previously (Prest et al., 2013). Briefly, a working solution of SYBR ${ }^{\circledR}$ Green I (SG) (Invitrogen AG, Basel, Switzerland) was prepared by 100x dilution in anhydrous dimethylsulfoxide (DMSO). Water samples and biofilm suspensions were stained with $S G$ at $10 \mu \mathrm{L} / \mathrm{mL}$. Samples were preheated to $35^{\circ} \mathrm{C}(3 \mathrm{~min})$, then incubated with stain in the dark for $10 \mathrm{~min}$ at $35^{\circ} \mathrm{C}$ before measurement. FCM measurements were performed on a BD Accuri $C 6{ }^{\circledR}$ instrument (BD Accuri cytometers, Belgium). Data analysis was performed using the BD Accuri CFlow ${ }^{\circledR}$ software, following the procedure described previously (Prest et al., 2013) to calculate total cell concentration (TCC). Water TCC was used directly (cells $/ \mathrm{mL}$ ) and biofilm TCC was calculated using the hose surface area $\left(\right.$ cells $\left./ \mathrm{cm}^{2}\right)$.

\subsection{Elemental Analysis}

Homogenized $100 \mathrm{uL}$ aliquots of the biofilm suspensions were acid-digested in $4 \mathrm{~mL}$ concentrated ultrapure $\mathrm{HNO}_{3}$ (Carl Roth $\mathrm{GmbH}$, Karlsruhe, Germany) and $1 \mathrm{~mL}$ ultrapure concentrated hydrogen peroxide (Sigma-Aldrich, Buchs, Switzerland) in $15 \mathrm{~mL}$ Teflon-tetrafluormetoxil (PTFE-TFM) tubes in an MLS ultraClave 4 (Milestone Inc., Shelton, USA) at $230^{\circ} \mathrm{C}$ and 130 bar for 35 minutes. 
Subsequently, digestates were diluted 10-fold with ultrapure deionised water. Quality control of digestion was performed by co-digesting procedural blanks and certified reference materials SRM 1568b (rice flour) and RTC SRM-008 (sediment), which gave elemental recoveries between 61$138 \%$ (Table S2).

Following digestion, elemental concentrations were quantified using a quadrupole dynamic reaction cell ICP-MS (Agilent $7500 \mathrm{cx}$ ). For each investigated element, the targeted isotope, reaction mode and detection limit ( $3 \times \sigma$ of $>10$ blanks) is given in Table S2. Instrumental tuning and calibration was performed daily and a $1 \mathrm{ppm} \mathrm{Sc}$ and $0.1 \mathrm{ppm}$ In and $\mathrm{Lu}$ in $1 \% \mathrm{HNO}_{3}$ solution was used as internal standard. Quality control was conducted by triplicate analysis of selected digestates and by analyzing procedural blanks and aqueous reference standards (Merck X and NIST 1643f).

\subsection{DNA extraction}

The remaining volume of biofilm suspension was filtered on a $0.2 \mu \mathrm{m}$ polycarbonate Nucleopore ${ }^{\circledR}$ membrane filter (47 mm diameter, Whatman, Kent, UK). The filter was inserted into a $5 \mathrm{~mL}$ tube and stored at $-20^{\circ} \mathrm{C}$ before DNA extraction with the Power Water DNA Isolation Kit (MoBio Laboratories, Inc., Carlsbad, CA) according to manufacturers' instructions.

\section{7. qPCR}

qPCR was used to quantify specific organisms, including L. pneumophila (via macrophage infectivity potentiator (mip) gene), M. avium, Acanthamoeba spp., and V. vermiformis using previously described protocols (Kuiper et al., 2006; Nazarian et al., 2008; Rivière et al., 2006; Wang et al., 2012; Wilton and Cousins, 1992). Reactions were performed using either a ABI7500 system (Thermo Fischer Scientific) for TaqMan (Bio-Rad) assays (L. pneumophila and Acanthamoeba spp.) or a LightCycler 480 for EvaGreen (Bio-Rad) assays ( $M$. avium and V. vermiformis) (Roche). Reactions and primers are detailed in Table S3. A 1:10 dilution was used for all samples, and standard curves using 7 standards on each run, with a limit of quantification (LOQ) of 10 gene copies/reaction. Only samples above the LOQ in duplicate reactions were considered to be positive for presence/absence assessment. 


\subsection{Amplicon sequencing with Illumina MiSeq}

Approximately $1 \mathrm{ng}$ of DNA extract from each sample was subjected to PCR amplification using modified universal bacterial primers Bakt_341F and Bakt_805R (Klindworth et al., 2013), which target the V3-V5 region of the 16S rRNA gene, and were adapted with a nucleotide tail to facilitate binding Nextera adapters. Index PCR was performed to add the Nextera XT v2 Index Kit adaptors (Illumina) to the amplicon. PCR reaction conditions are detailed in (Table S4). After each PCR reaction, products were purified using the Agencort ${ }^{\circledR}$ AMPure ${ }^{\circledR}$ XP system (Beckman Coulter, Inc., Bera, CA).

Each product was quantified using Qubit 2.0 HS DNA system (Thermo Fisher Scientific). Samples were normalized to the same concentration before running on the MiSeq platform using MiSeq Reagent Kit v2 (300-cycles, \#MS-102-2002) according to manufacturer's protocol with 10\% PhiX. All sequencing was done at the Genetic Diversity Centre (GDC) of ETH, Zurich. Libraries were produced separately for the global survey and the follow-up study.

\subsection{Statistical analysis}

For correlations in the global survey, non-parametric tests (Spearman, Kruskal-Wallis, as labelled) were used because data was not normally distributed. Parametric tests (Pearson's correlation) were used to quantify correlations in the follow-up study.

For sequencing data, sequences were merged, trimmed, filtered, and clustered into operational taxonomical units (OTUs) according to several algorithms (Table S5). Sequences were identified according to greengenes v.13.5 (DeSantis et al., 2003). In R, phyloseq (McMurdie and Holmes, 2013) was used for processing. Libraries were rarefied to either 37,629 (global survey) or 82,185 (follow-up) sequences per sample. In this process, two samples from Switzerland (global survey) were removed from analysis due to low number of reads. Non-metric multidimensional scaling (NMDS) was used to visualize microbiome similarities using Bray-Curtis dissimilarity. The adonis and ordiellipse functions from the vegan package (Oksanen et al., 2013) were used to relate environmental data to microbiome composition. In the follow-up, the number of core OTUs was calculated as the OTUs present in all locations of each sample type or overlapping type. 


\section{Results}

For each section, results are presented separately for the two experiments - the global survey and follow-up study. In the global survey, 78 shower hoses with largely unknown histories were collected from 11 countries. In the follow-up study, 15 identical PVC-P shower hoses were installed in Swiss homes and collected after 1.5 years of use, together with three types of water samples from each location.

\subsection{Biofilm concentrations were high but variable}

Global survey

Biofilm thickness as measured by OCT ranged from non-detectable to $0.40 \mathrm{~mm}$ (Figure 1 ). Thickness varied considerably across different hoses, but also along a single shower hose (two ends 90-100 cm apart) (Figure S1). SEM imaging of a representative biofilm indicates a thick matrix of cellular, non-cellular organic, and inorganic constituents (Figure 1, Figure S2).

The biofilm surface concentration (hereafter, biofilm concentration) was measured with several methods using the biofilm suspension from the $90-\mathrm{cm}$ section of hose. Biofilm total cell concentration (biofilm TCC) measured with FCM ranged from $4.1 \times 10^{4}-5.8 \times 10^{8}$ cells $/ \mathrm{cm}^{2}$ (Figure $2 \mathrm{~A}$ ), with an average of $4.4 \times 10^{7}$ cells $/ \mathrm{cm}^{2}$ on each hose. Other measures of biofilm concentration, including the biofilm concentrations of intact cells and adenosine tri-phosphate, correlated well with biofilm TCC (Spearman's $\rho=0.95$ and 0.87 respectively, $p<0.001$, Figure S3). Biofilm concentrations of $16 \mathrm{~S}$ rRNA genes (qPCR), total organic carbon (TOC), and optical density $\left(\mathrm{OD}_{546}\right)$ did not correlate well with biofilm TCC (Spearman's $\rho=0.52,0.57$, and 0.65 respectively, $p<0.001$ ). Since TOC includes extracellular polymeric substances (EPS), and $\mathrm{OD}_{546}$ is influenced by inorganics (e.g., calcium, and iron), these can serve as proxies for sliminess and color, which are otherwise hard to quantify (discussed further with Figure S3).

Biofilm TCC varied significantly based on country of origin, and this between-country variation seemed to be related to the use/non-use of disinfectant. When comparing biofilm TCC between countries that used disinfectant (Belgium, Latvia, Portugal, Serbia, UK, and US, N=39) and 
those that did not (Denmark, Germany, South Africa, Spain, and Switzerland N=39), biofilm TCC was significantly higher without disinfectant $(p<0.001$, Kruskal-Wallis, Figure $2 A)$. This dichotomous classification for disinfectant use/non-use oversimplifies the situation. For example, many utilities in South Africa typically use disinfectants, but the samples were taken from homes using untreated borehole water. Also, some systems (e.g., Belgium) were known to use only low concentrations, and other systems (e.g., Latvia) were known for disinfectant loss in distribution. However, switching of these 'border-line' cases (e.g., Belgium, Latvia) did not affect the overall results.

Follow-up study

In the follow-up study, biofilm TCC ranged between $0.3-2.0 \times 10^{8}$ cells $/ \mathrm{cm}^{2}$ (average $7.76 \times 10^{7}$ cells $\left./ \mathrm{cm}^{2}\right)$, which is a narrower range compared to the same 15 locations in the global survey $(0.04$ $-1.2 \times 10^{8}$ cells $/ \mathrm{cm}^{2}$, average $5.36 \times 10^{7}$ cells $/ \mathrm{cm}^{2}$ ). In 9 of 15 locations, biofilm TCC was higher during the follow-up study than in the global survey (Figure 3A). This occurred even though hoses were usually older during the global survey than in the follow-up study (hoses from 12 of 15 followup sample locations were estimated to be $>2-8$ years old during the global survey, while 3 were known to be $<6$ months old).

\subsection{Frequency of use may affect biofilm concentrations}

Water TCC varied amongst the three types of water samples collected in the follow-up study (Figure 4A), with stagnant water having the highest TCC in 12 of 15 locations. To relate the water phase to biofilm, additional water quality parameters for the cold flowing water and use-patterns were also measured (Table S6). While water quality did not correlate well with biofilm TCC (data not shown), biofilm TCC correlated positively with the frequency of use (Pearson's $R=0.72$, $p=0.004$, Table S7).

\subsection{Metals accumulate in biofilms}


281 Color was notably variable across biofilms (e.g., deep red/orange, translucent, white, yellow) 282 (Figure 5, Figure S4). Presumably, this can be attributed partly to metal deposition. While not de283 tected in all biofilms, biofilm concentrations of iron, lead, and copper were as high as $5 \mu \mathrm{g}-\mathrm{Fe} / \mathrm{cm}^{2}$ 284 (South Africa), $75 \mathrm{ng}-\mathrm{Pb} / \mathrm{cm}^{2}$ (Denmark), and $460 \mathrm{ng}-\mathrm{Cu} / \mathrm{cm}^{2}$ (Latvia). These metals all correlated 285 to one another (Spearman's $\rho>0.75, p<0.001$ ), and correlated moderately with optical density of 286 biofilm suspensions (data not shown, correlations only driven by several high points). Calcium and magnesium were detected in all biofilms, and correlated separately with one another (Spearman's $\rho=0.6, p<0.001)$, as might be expected with sorption behavior. There were no strong correlations between these metals and biofilm TCC (Figure S5).

Follow-up study

The concentration of metals tended to be higher during the global survey when hoses were older than during the follow-up study (Figure 3B,C,D). Concentrations were more similar when hoses were from the same building and had similar ages (e.g., Hoses 3-6 were from one building and had similar ages in both experiments Figure 3B,C,D).

\subsection{Microbiome composition reveals a diverse ecological niche in biofilms}

Global survey

The number of OTUs observed in each biofilm ranged from 74 to 481 . This measure of diversity correlated significantly but weakly with biofilm TCC (Spearman's $\rho=0.28, p=0.01$ ), and was significantly lower amongst biofilms in countries that use disinfectant ( $p=0.01$, Kruskal-Wallis, Figure 2B).

Some similarities could be seen in biofilm microbiome compositions from the same country

(Figure 6A), but country only explains $24 \%$ of variation in microbiome composition (Adonis, $p<0.001)$. Use of disinfectant was not useful for explaining microbiome composition (4\% explained by disinfectant use, Adonis, $p<0.001$, Figure $6 B$ ). However, countries consistently using strong disinfectant residuals (US, UK, Portugal) cluster at a high positive NMDS1. The most abundant OTUs 
may drive some of these variations, with the sum of the top ten OTUs accounting for $3-41 \%$ of individual microbiomes. This proportion varied by country (Kruskal-Wallis, $p<0.001$ ) and was significantly higher when disinfectant was used (Kruskal-Wallis, $p<0.001)$.

Interestingly, biofilm TCC also seemed to be related to microbiome composition. Biofilm TCC correlated with the relative abundance of several of the ten most abundant genera (Figure S6). Significant negative correlations were found with Sphingomonas, Pseudomonas, and Limnobacter (Spearman's $\rho=-0.56,-0.55,-0.47$, respectively, $p<0.001$ ), while positive correlations were found with Dok59, Sphingobium, and Meiothermus (Spearman's $\rho=0.57(p<0.001), 0.21(p=0.17)$, $0.21(p=0.12)$, respectively).

\section{Follow-up study}

Amongst water samples, cold flowing water had the highest number of OTUs, followed by warm water and stagnant water (Figure 4B). The biofilm had a much lower diversity than all of the water samples (e.g., between 90 and 98\% fewer OTUs than cold water, (Figure 4B)).

Microbiome composition also varied between three types of water samples and the biofilm (Figure 4C). Even at the phylum and class level, each sample type clearly harbored different types of bacteria (Figure 7). Three taxa (Betaproteobacteria, Alphaproteobacteria, and Bacteroidetes) that accounted for $91 \%$ of biofilm sequences, only accounted for $31 \%$ of the cold influent water microbiome. Seven taxa (OD1, OP3, Deltaprotobacteria, Planctomycetes, Chloroflexi, Chlamydiae, and Nitrospirae) that accounted for $51 \%$ of cold-water microbiomes only accounted for $2 \%$ of biofilm microbiomes. Another four taxa (Acidobacteria, Actinobacteria, Deinococcus-Thermus, and TM7) were enriched in warm water (16\%). Core OTUs were also distinct between the sample types, with only 6 OTUs shared by all samples (Figure 7). Sample type, however, only explained $18 \%$ of microbiome variation (Adonis, $\mathrm{p}<0.001$ ). Household explained $41 \%$ of microbiome variation (Adonis, $p<0.001$, Figure S7).

\subsection{Specific organisms in shower hose biofilms may present risk}


Two opportunistic pathogens, Mycobacterium avium and Legionella pneumophila, and two amoebae, Acanthamoeba ployphaga and Verbamoeba vermiformis, were detected via qPCR in 11, 21, 4 , and 21 hoses respectively. The maximum concentrations on these hoses was $6.6 \times 10^{7}$ gene copies $(\mathrm{gc}) / \mathrm{cm}^{2}, 6.6 \times 10^{5} \mathrm{gc} / \mathrm{cm}^{2}, 2.5 \times 10^{4} \mathrm{gc} / \mathrm{cm}^{2}$, and $2.8 \times 10^{5} \mathrm{gc} / \mathrm{cm}^{2}$, respectively. L. pneumophila co-occurred with a potential amoebae host ( $V$. vermiformis) in six hoses, and it cooccurred with M. avium in two hoses.

Several genera that might include opportunistic pathogens were also detected in sequencing data. Legionella, Mycobacterium, and Pseudomonas were detected in 43, 64, and 34 hoses respectively. While 31 of 34 Pseudomonas positive hoses were also positive for Mycobacterium, only 14 were also positive for Legionella. 37 hoses were positive for both Legionella and Mycobacterium, and 13 hoses were positive for all three genera of interest. Some countries had higher occurrences: Legionella was detected in 9 of 10 hoses in Denmark; Mycobacterium was detected in all hoses in Belgium, Germany, Latvia, South Africa, Serbia, UK, and US; and Pseudomonas was detected in 8 of 9 hoses in UK.

Absolute abundance of these genera was calculated by multiplying the relative abundance with TCC (as done previously (Props et al., 2016)), yielding in some cases substantial maximum concentrations of these genera: Legionella $\left(7.8 \times 10^{5}\right.$ cells $/ \mathrm{cm}^{2}$, Belgium), Mycobacterium (4.1 $\mathrm{x}$ $10^{7}$ cells $/ \mathrm{cm}^{2}$, Belgium), and Pseudomonas $\left(3.1 \times 10^{6} \mathrm{cells} / \mathrm{cm}^{2}\right.$, Switzerland). One hose from the UK had the highest relative abundance of Mycobacterium (35\%), but because biofilm TCC was low, it only had the $17^{\text {th }}$ highest concentration by calculated absolute abundance $\left(5.9 \times 10^{5} \mathrm{cells} / \mathrm{cm}^{2}\right)$. A hose from Belgium only had 16\% Mycobacterium, but had 2-orders of magnitude higher absolute abundance $\left(2.1 \times 10^{7}\right.$ cells $\left./ \mathrm{cm}^{2}\right)$.

When Legionella was detected, biofilm TCC was significantly higher (Kruskal-Wallis, $\mathrm{p}<0.001$ ) (Figure 8A), indicating that Legionella is more likely to be found with a higher biofilm TCC. There was also a significant positive correlation between Legionella relative abundance and biofilm TCC (Spearman's $\rho=0.36, p<0.001$ ). However, for Mycobacterium and Pseudomonas, detection was associated with reduced biofilm TCC (Kruskal-Wallis, $p=0.06$, and $<0.001$ respectively) (Figure 8D,E). Biofilm TCC was not a predictor for detection for L. pneumophila, M. avium, or V. 
366 vermiformis (Figure 8B,C,F), but results may have been influenced by the relatively few detects 367 with qPCR.

368

369 Follow-up study

370 Surprisingly, cold influent water was frequently positive for low concentrations of Legionella (12/12), 371 Mycobacterium (12/12), and Pseudomonas (11/12). Biofilms were more sporadically positive for 372 these genera (Legionella 6/15, Mycobacterium 7/15, and Pseudomonas 13/15). However, these 373 three genera had the highest calculated absolute abundances in stagnant water samples $\left(6.8 \times 10^{3}\right.$, $3746.9 \times 10^{3}$ and $6.2 \times 10^{2}$ cells $/ \mathrm{mL}$ respectively for Legionella, Mycobacterium, and Pseudomonas), 375 and these maximums corresponded with biofilm detection of the genera. 


\section{Discussion}

The shower hoses used in this study all originated from real homes, and were thus subject to many unknown and uncontrolled factors contributing to biofilm formation and microbiome composition.

381 These selective forces include, amongst others, material properties (hose composition and age), 382 user-specific properties (frequency of use, temperature), biofilm properties (e.g., biofilm cell concentration, iron providing oxidizing agents, copper providing toxicity), and selective forces on the water earlier in distribution (e.g., chlorine, water microbiome composition and abundance). Even with the more controlled follow-up study, multiple factors simultaneously contribute to observed results, and it is challenging to disentangle selective forces from one another. However, some trends and specific interesting examples were observed and are discussed below.

\subsection{Shower hoses harbor many bacteria.}

The characteristics common to nearly all shower hoses, including mild-to-warm temperatures (ranging from room temperature to maximum shower temperatures of c.a. $43^{\circ} \mathrm{C}$ ), long stagnation, and nutrient migration from flexible plastic materials (Proctor et al., 2016) likely contribute to high biofilm TCC. Although variable, biofilm TCC tended to be higher on shower hoses (average $10^{7}$ cells $/ \mathrm{cm}^{2}$ ) than on hard pipe materials typically used in building plumbing (copper and PEX pipes, $\sim 5.7 \times 10^{5}$ cells $/ \mathrm{cm}^{2}$, (Inkinen et al., 2014)) or plumbing simulators (Pe-Xc, $\sim 2 \times 10^{6} \mathrm{cells} / \mathrm{cm}^{2}$ (Proctor et al., 2016)). However, comparison of biofilm data between different studies is influenced by differences in sampling and analysis methods (Wang et al., 2017). In addition to bacteria, biofilms also harbor non-bacterial cells (e.g., amoebae) and non-cellular organic and inorganic matter (e.g., EPS, metals), such that thick, complex environments emerge (Figure 1). 
The use of disinfectants during water treatment can lower both the concentration (Prest et al., 2016) and diversity (Bautista-de los Santos et al., 2016) of bacteria in water. It is unclear, however, how this would affect biofilms at the distal end of building plumbing systems, where disinfectant residual is often lost (Lipphaus et al., 2014). In the present study, disinfected drinking water resulted in biofilms with lower TCC, decreased diversity, and increased relative abundance of the ten most abundant OTUs (Figure 2, Figure 6). It could thus be argued that either (1) residual disinfectant acts as a selective force directly on biofilms, or (2) disinfectant acts as an indirect selective force, reducing the diversity in the source water which in turn reduces the diversity in the seed available for biofilm colonization. With purely stochastic immigration to the biofilm, diversity in the metacommunity (in this case, the influent water) would be reflected in the biofilm microbiome (Battin et al., 2007). Since several countries with relatively high disinfectant residuals clustered closer together (Figure 6B), prolonged exposure to disinfectant may be more selective (e.g., a surviving 'resistome' (Jia et al., 2015)).

\subsection{Shower hose material quality is a problematic unknown.}

The amount and type of carbon leaching from plastic pipe materials is critical for determining biofilm concentration and composition (Proctor et al., 2016; Wen et al., 2015). Composition of hoses in the global survey was clearly variable (Figure 5), but unknown, and therefore no reasonable conclusions can be inferred. In contrast, identical PVC-P hoses were used in the follow-up study. This specific material encouraged biofilm proliferation more than other materials (up to $2 \times 10^{8}$ cells $/ \mathrm{cm}^{2}$ over 8 months) (Proctor et al., 2016) and this was linked to carbon leaching: under optimal conditions, PVC-P hoses leached large amounts of biodegradable carbon $\left(9.7 \mu \mathrm{g}-\mathrm{C} / \mathrm{cm}^{2}\right.$ supporting $4.8 \times 10^{7}$ cells $/ \mathrm{cm}^{2}$ in 7 days). The generally higher biofilm concentrations during the followup study (Figure $3 \mathrm{~A}$ ) may thus be linked to the common material. However, leaching behavior is variable, with an initial peak diminishing over time (Bucheli-Witschel et al., 2012). Thus, the common young age of the materials in the follow-up study can also contribute to the high, narrow range of biofilm TCC (discussed further below). 


\subsection{Are new shower hoses worse than old ones?}

Within the same household, accumulation of metals in biofilms seemed to increase with age

(Figure 3B-D), but this was difficult to confirm, since age of hoses during the survey was usually unknown beyond a minimum (e.g., time of move-in). Furthermore, while passive metal accumulation likely increases with time, primary biofilm development may involve active accumulation (e.g., iron as trace nutrient, calcium as biofilm structural support).

Biofilm TCC is dependent on availability of nutrients for growth. Carbon leaching diminishes over time (Bucheli-Witschel et al., 2012), resulting in a nutrient-rich environment in new hoses, and a nutrient-poor environment in old hoses. Other nutrients necessary for growth (e.g., $\mathrm{N}$ and $\mathrm{P}$ ) are typically present in oligotrophic concentrations in drinking water, and thus enter the shower hose based on use frequency over time. Here, in cases where hose age could be estimated (ranging 3 months to 30 years), there was no correlation with biofilm TCC (data not shown). The hose with the most biofilm $\left(5.8 \times 10^{8} \mathrm{cells} / \mathrm{cm}^{2}\right)$ was only installed for one year, and TCC was often higher in the younger biofilms during the follow-up study (Figure 3A). This lack of correlation between age and biofilm concentration is not unprecedented (Wingender and Flemming, 2004). It is likely that a growth plateau is reached quickly with shower hose biofilms due to the fast leaching of considerable amounts of carbon (Proctor et al., 2016; Wen et al., 2015).

\subsection{Metals from the building accumulate at the shower hose.}

The biofilm concentrations of metals were similar in hoses from the same buildings (Figure 3B-D, with hoses 3-6 from the same building). While some (calcium and magnesium) are presumably related to local influent water quality (e.g., hardness), it is likely that others (lead, copper, iron) at least partially originate from other pipes and fittings in the building (Gonzalez et al., 2013). While the latter group can also accumulate from trace concentrations in the water, pipe corrosion is a well-known problem and information about building plumbing materials is generally not well documented or known to consumers. Risks from lead in pipes and brass fittings are known, but regulations attempting to limit these lead risks are not applied retroactively to replace building plumbing components, and building plumbing still contributes significantly to lead in water (Haider et al., 
2002). Metals can also leach from plastic pipes (e.g., lead is used as a stabilizer for certain PVC plastics (Zhang and Lin, 2015)).

\subsection{Specific use patterns affect biofilms.}

Frequency of use has previously been shown to affect tap-specific colonization of opportunistic pathogens (Rudi et al., 2009) and microbiomes in a model hot water distribution system (Ji et al., 2017). Here, the more frequently used hoses in the follow-up study had higher biofilm TCC. With their stagnation patterns, shower hoses could be thought of as batch reactors. Nutrient loads (other than carbon provided by the hose) would then be determined by frequency of use and concentration in water (Table S7). Interestingly, the three hoses with the highest biofilm concentration were used frequently during the workweek, but only rarely on weekends. Thus, nutrient loads were high and stagnation was irregular. Since frequent use both supplies nutrients and potentially disrupts biofilms by changing hydraulics and delivering stress elements (e.g., chlorine, heat), the complexities of irregular use are interesting for future research. Here, in the follow-up study, residual chlorine was not present, but the hose with the lowest biofilm concentration was typically only used for high temperature cleaning of the tub $\left(70^{\circ} \mathrm{C}\right)$, essentially providing a heat-shock to the biofilm.

\subsection{The microbiome of a building plumbing system is explained by drift and selection.}

In the follow-up study, household explained much of the microbiome variation (i.e., water and biofilm samples were similar within a household (Figure S7)). This might be expected as the microbiology of the entire building's plumbing system is inevitably dictated by drift from the cold distribution system water. However, the differences between various water sample types and biofilms were evident across households in terms of TCC, diversity, and microbiome composition (Figure 4, Figure 7). If one considers the path water takes through the home as a microbiome continuum (Proctor and Hammes, 2015), then one can explain these changes through the concepts of drift and selection.

Warm water was less diverse and had lower TCC than cold water. Together with the enrichment of Deinococcus-Thermus (Figure 7), which consists almost entirely of extremophiles, this 
indicates water heater stress as a strong selective force. Negative relationships between diversity and temperature were previously observed in building plumbing simulators (Ji et al., 2017). However, cold and warm water samples still shared 23 core OTUs. While cold water is the source and metacommunity for warm water, warm water was collected only at moderate temperatures (35$40^{\circ} \mathrm{C}$, i.e., mixing of cold and hot water), and thus there was also direct drift from cold water. Stagnant water was similar in terms of water TCC, diversity and composition, to its source and metacommunity, the warm water. However, drift from the biofilm phase (i.e., biofilm detachment during stagnation) increased TCC and lowered diversity as the microbiome converged with biofilm microbiomes (Figure 4, Figure 7). Phylogenetic convergence between stagnant water and biofilm samples has been noted previously (Inkinen et al., 2014), and might be tied to the duration of stagnation (Ji et al., 2017).

Biofilms all had low diversity compared to water, and were also different from each other, with only 8 OTUs shared by all biofilms (Figure 7). Organic carbon leaching from the hoses likely provide a positive selective force, and PVC-P is specifically known to select for a low diversity in biofilms compared to other materials (Proctor et al., 2016). Growth in biofilms might be a selective force in and of itself, as reduced diversity in biofilms compared to water has been noted previously in building plumbing (Inkinen et al., 2016) and a chlorinated distribution system (Douterelo et al., 2017), but not a non-chlorinated distribution system (Liu et al., 2014).

\subsection{Biofilm composition is driven by multiple factors that co-vary with biofilm TCC.}

Biofilm TCC seemed to drive some components of microbiome composition (Figure S6).

While some bacteria may be affected by biofilm thickness itself (e.g., more diverse niche space in thick biofilms with localized gradients (Flemming et al., 2016)), multiple selective forces can affect biofilm TCC and composition simultaneously. For example, Sphingomonas had a negative correlation with biofilm TCC. It is resistant to chlorine (Jia et al., 2015), and thus disinfectant may be acting as a selective force that dictates both Sphingomonas abundance and biofilm TCC. Limnobacter also had a negative correlation with biofilm TCC, but is susceptible to chlorine (Jia et al., 2015). Since it can degrade phenol (Vedler et al., 2013) which leaches from some plastic pipes (Skjevrak et al., 2003), this suggests the positive selective force of plastic pipes when growth conditions are 
otherwise non-ideal. Meiothermus is an interesting example of a genus positively correlating with biofilm TCC. It is slightly thermophilic, has a reddish color, causes biofouling, and has been isolated in geothermal springs with iron oxidizing activity (Kolari et al., 2003; Urbieta et al., 2015). Here, Meiothemus accounted for $12 \%$ of two notably red biofilms from South Africa (Figure S4B) with high iron concentrations $\left(0.09\right.$ and $\left.5 \mu \mathrm{g} / \mathrm{cm}^{2}\right)$, suggesting that temperature, iron oxidation, and high biofilm cell concentrations were all contributing selective factors for the presence of this organism.

\subsection{These biofilms hold some risk.}

Toxic metals and potential opportunistic pathogens were found in shower hose biofilms. Metals exposure is through consumption (drinking), and thus exposure from showers is low, but not obsolete (e.g., brushing teeth in shower). Additionally, sporadic detection of particulate lead is not uncommon in building water (Deshommes et al., 2010), and could result from biofilm detachment (i.e., dislodged during hose manipulation). However, concentrations of metals tended to be lower than detected in distributions systems (Lehtola et al., 2004), and thus these biofilms are unlikely to be a major contributor to risk.

All of the reported opportunistic pathogens present a risk specifically for showering, with routes of infection either through inhalation or wound exposure (Falkinham et al., 2015). It is difficult to interpret the clinical relevance of the concentrations, since little is understood about (1) how these biofilms detach into the water phase and (2) what dose is required for infection. Moreover, for reported genera derived from sequencing data, species and strain level definition was not possible, and thus these do not necessarily present risks.

A common argument for biofilm control is that reducing total biofilm also reduces risk of exposure to opportunistic pathogens. However, biofilm concentration likely co-varies with or affects biofilm microbiome composition (as discussed above). L. pneumophila is thought to proliferate in thick biofilms, and recently, a threshold biofilm concentration for L. pneumophila growth was proposed at $10^{6}$ cells $/ \mathrm{cm}^{2}$ (van der Kooij et al., 2017). Most of our biofilm concentrations were above this threshold, and L. pneumophila was even detected below the proposed threshold. Although a positive relationship between TCC and L. pneumophila was not found (Figure 8B), Legionella data 
correlated positively with TCC (Figure 8A), indicating that decreasing biofilm concentration can protect against this particular risk.

Other opportunistic pathogens may have a negative correlation with biofilm TCC (e.g., Mycobacterium and P. aeruginosa (Meier and Bendinger, 2016; Proctor et al., 2016)), or with other opportunistic pathogens (e.g., Legionella with P. aeruginosa (Leoni et al., 2001)). In this study, Mycobacterium and Pseudomonas correlated negatively with biofilm TCC (Figure 8D,E), and cooccurred with each other more than with Legionella. In a study of shower hose biofilms exposed to chlorine residual in the US, Mycobacterium dominated (Soto-Giron et al., 2016), and thus disinfectant resistance may play a role in these correlations. With biofilm management strategies, it is necessary to weigh the risks of many potential pathogens at the same time. Reducing biofilm concentration (i.e. with disinfectant) may reduce risk from some potential pathogens while increasing risk from others.

Stagnant water, which is influenced by detached biofilm, had the highest potential risk of the three water types tested. However, biofilm was not the only source for these genera, since the cold water was also frequently positive for potential opportunistic pathogens. In a previous study of showers in the UK, only $40 \%$ of stagnant water samples positive for Legionella were also positive in shower hose biofilm swabs (Collins et al., 2017), further indicating that other sources (e.g., cold water distribution systems) are likely important in shower exposure.

\subsection{Shower hose biofilms represent a meaningful sampling point.}

Water samples are the easiest type of sample to collect from household plumbing (Wang et al., 2017). However, $<2 \%$ of bacterial biomass of distribution systems is present in the planktonic phase, with most biomass in biofilms and loosely deposited material (Liu et al., 2014). Our data, in combination with the little available evidence on real shower environments (Collins et al., 2017; Feazel et al., 2009; Soto-Giron et al., 2016), suggest that opportunistic pathogens are harbored in shower-related biofilms. Shower hoses offer one of the most convenient sampling locations for biofilm monitoring in building plumbing. Most components of building plumbing are not removable and are difficult to sample (e.g., manual swabbing), thus limiting reproducibility and representativeness. In contrast, shower hoses can be removed and replaced, offering large sections $\left(350-800 \mathrm{~cm}^{2}\right)$ of 
578 easily accessible biofilms. Such a biofilm-based approach will complement the wealth of 579 knowledge on building plumbing water, and is necessary for a more complete understanding of 580 ecology and risk in household plumbing.

\section{$582 \quad 4.11$ Shower hoses can be managed better.}

583 Shower hoses offer a critical area for improvement of building plumbing management strategies. 584 These hoses typically fall outside potable water material regulations, but clearly microbiology 585 needs to be considered. As it stands, consumers assume all risks and receive little guidance about 586 this portion of easily controlled building plumbing. Moreover, shower hoses are not necessary for 587 all homes, and could be replaced with safer hard pipe material. Hospitals and old-age homes are 588 generally better informed about limiting risk from shower environments. Programs for quarterly 589 shower hose and head replacement aimed at reducing risk are available for such facilities (Table 590 S8). Given the tenuous relationship between age and biofilm TCC in this study, a more aggressive 591 strategy, like single-use shower hoses (Table S8), may be necessary for high-risk patients. 


\section{Conclusions}

In a global survey and follow-up study, shower hoses from all over the world were characterized in detail in terms of biofilm concentrations, metals accumulation, and microbiome composition. While many factors were uncontrolled, some trends were apparent:

\section{Acknowledgements}

- When disinfectants were used, cell concentrations and diversity were reduced.

- Young shower hose age and bad material quality likely contributed to high cell concentrations.

- Frequent, but irregular use likely contributed to high cell concentrations.

- The microbiome along the path of water delivery in a building could be explained by drift and selection.

- Biofilm microbiome composition was shaped by several factors, some of which co-varied with cell concentration.

- Potential opportunistic pathogens were detected, with either a positive (Legionella) or negative (Mycobacterium, Pseudomonas) correlation with cell concentration.

- Metals accumulated over time in biofilms, likely originating from other building plumbing components.

While more controlled studies can further explore these trends, it was abundantly clear that shower hoses offer a perfect biofilm sampling point to complement building water studies, and that shower hoses should be considered in building plumbing risk management strategies.

The authors acknowledge financial support from MERMAID, a Marie Sklodowska-Curie Initial Training Network, under grant no. 607492, and the Swiss National Science Foundation (SNF grant number 31003A_163366/1). Jurg Sigrist and Lisa Neu contributed to lab-work. Standards for opportunistic pathogen qPCR reactions were supplied by the lab of Amy Pruden (Virginia Tech), with special thanks to Emily Garner for coordination. Karin Beck and Helmut Bürgmann assisted with 
621 16S qPCR data acquisition and evaluation. Sequencing data analyzed in this paper were generat622 ed in collaboration with the Genetic Diversity Centre (GDC), ETH Zurich, with support and proto623 cols from Aria Minder and Silvia Kobel, and with raw sequencing data analysis performed by Jean624 Claude Walser. Lastly, the authors thank all sample volunteers, especially local coordinators, in625 cluding Marta Vignola, Ameet Pinto, Marta Kinnunen, Svetlana Perovic, Stefanie Imminger, Xiaofei 626 Wang, Alina Nescerecka, and Sam Van Nevel.

627 


\section{References}

Battin, T.J., Sloan, W.T., Kjelleberg, S., Daims, H., Head, I.M., Curtis, T.P., Eberl, L., 2007. Microbial landscapes: new paths to biofilm research. Nat. Rev. Microbiol. 5, 76-81. doi:10.1038/nrmicro1556

Bautista-de los Santos, Q.M., Schroeder, J.L., Sevillano-Rivera, M.C., Sungthong, R., ljaz, U.Z., Sloan, W.T., Pinto, A.J., 2016. Emerging investigators series: microbial communities in fullscale drinking water distribution systems - a meta-analysis. Environ. Sci. Water Res. Technol. 2, 631-644. doi:10.1039/C6EW00030D

Beer, K.D., Gargano, J.W., Roberts, V.A., Hill, V.R., Garrison, L.E., Kutty, P.K., Hilborn, E.D., Wade, T.J., Fullerton, K.E., Yoder, J.S., 2015. Surveillance for Waterborne Disease Outbreaks Associated with Drinking Water - United States, 2011-2012. MMWR. Morb. Mortal. Wkly. Rep. 64, 842-8.

BMJV, 2011. The German Federal Ministry of Justice and Consumer Protection. Ordinance on the Quality of Water for Human Use (Drinking Water Ordinance TrinkwV 2011).

Bucheli-Witschel, M., Kötzsch, S., Darr, S., Widler, R., Egli, T., 2012. A new method to assess the influence of migration from polymeric materials on the biostability of drinking water. Water Res. 46, 4246-4260. doi:10.1016/j.watres.2012.05.008

BVer LMG, 2017. The Federal Assembly of the Swiss Confederation. Federal Act on Foodstuffs and Utility Articles (817.0).

CEN, 2013. European Committee for Standardization. EN 16421. Influence of materials on water for human consumption - Enhancement of microbial growth (EMG).

Collins, S., Stevenson, D., Bennett, A., Walker, J., 2017. Occurrence of Legionella in UK household showers. Int. J. Hyg. Environ. Health 220, 401-406. doi:10.1016/j.ijheh.2016.12.001

DeOreo, W., Mayer, P., Dziegielewski, B., Kiefer, J., 2016. Residential End Uses of WaterVersion 2. Denver, CO.

DeSantis, T.Z., Dubosarskiy, I., Murray, S.R., Andersen, G.L., 2003. Comprehensive aligned sequence construction for automated design of effective probes (CASCADE-P) using 16S rDNA. Bioinformatics 19, 1461-8. 
Deshommes, E., Laroche, L., Nour, S., Cartier, C., Prévost, M., 2010. Source and occurrence of particulate lead in tap water. Water Res. 44, 3734-3744. doi:10.1016/j.watres.2010.04.019

Douterelo, I., Jackson, M., Solomon, C., Boxall, J., 2017. Spatial and temporal analogies in microbial communities in natural drinking water biofilms. Sci. Total Environ. 581, 277-288. doi:10.1016/j.scitotenv.2016.12.118

EDI, 2016. The Swiss Federal Department of Home Affairs. Regulation of the EDI about drinking water and water in publicly accessible baths and showers. (TBDV) 807.022.11.

Falkinham, J.O., Hilborn, E.D., Arduino, M.J., Pruden, A., Edwards, M.A., 2015. Epidemiology and Ecology of Opportunistic Premise Plumbing Pathogens: Legionella pneumophila, Mycobacterium avium, and Pseudomonas aeruginosa. Environ. Health Perspect. 123, 749-58. doi:10.1289/ehp.1408692

Feazel, L.M., Baumgartner, L.K., Peterson, K.L., Frank, D.N., Harris, J.K., Pace, N.R., 2009. Opportunistic pathogens enriched in showerhead biofilms. Proc Natl Acad Sci U S A 106, 16393-16399. doi:10.1073/pnas.0908446106

Flemming, H.-C., Wingender, J., Szewzyk, U., Steinberg, P., Rice, S.A., Kjelleberg, S., 2016. Biofilms: an emergent form of bacterial life. Nat. Rev. Microbiol. 14, 563-575. doi:10.1038/nrmicro.2016.94

Gonzalez, S., Lopez-Roldan, R., Cortina, J.-L., 2013. Presence of metals in drinking water distribution networks due to pipe material leaching: a review. Toxicol. Environ. Chem. 95, 870-889. doi:10.1080/02772248.2013.840372

Haider, T., Haider, M., Wruss, W., Sommer, R., Kundi, M., 2002. Lead in drinking water of Vienna in comparison to other European countries and accordance with recent guidelines. Int. J. Hyg. Environ. Health 205, 399-403. doi:10.1078/1438-4639-00164

Inkinen, J., Jayaprakash, B., Santo Domingo, J.W., Keinänen-Toivola, M.M., Ryu, H., Pitkänen, T., 2016. Diversity of ribosomal 16S DNA- and RNA-based bacterial community in an office building drinking water system. J. Appl. Microbiol. 120, 1723-1738. doi:10.1111/jam.13144 Inkinen, J., Kaunisto, T., Pursiainen, A., Miettinen, I.T., Kusnetsov, J., Riihinen, K., KeinänenToivola, M.M., 2014. Drinking water quality and formation of biofilms in an office building during its first year of operation, a full scale study. Water Res. 49, 83-91. 
Ji, P., Rhoads, W.J., Edwards, M.A., Pruden, A., 2017. Impact of water heater temperature setting and water use frequency on the building plumbing microbiome. ISME J. doi:10.1038/ismej.2017.14

Jia, S., Shi, P., Hu, Q., Li, B., Zhang, T., Zhang, X.-X., 2015. Bacterial Community Shift Drives Antibiotic Resistance Promotion during Drinking Water Chlorination. Environ. Sci. Technol. 49, 12271-12279. doi:10.1021/acs.est.5b03521

Kilvington, S., Gray, T., Dart, J., Morlet, N., Beeching, J.R., Frazer, D.G., Matheson, M., 2004. Acanthamoeba keratitis: the role of domestic tap water contamination in the United Kingdom. Invest. Ophthalmol. Vis. Sci. 45, 165-9.

Klindworth, A., Pruesse, E., Schweer, T., Peplies, J., Quast, C., Horn, M., Glöckner, F.O., 2013. Evaluation of general $16 \mathrm{~S}$ ribosomal RNA gene PCR primers for classical and nextgeneration sequencing-based diversity studies. Nucleic Acids Res. 41, e1. doi:10.1093/nar/gks808

Kolari, M., Nuutinen, J., Rainey, F.A., Salkinoja-Salonen, M.S., 2003. Colored moderately thermophilic bacteria in paper-machine biofilms. J. Ind. Microbiol. Biotechnol. 30, 225-38. doi:10.1007/s10295-003-0047-z

Kuiper, M.W., Valster, R.M., Wullings, B.A., Boonstra, H., Smidt, H., van der Kooij, D., 2006. Quantitative detection of the free-living amoeba Hartmannella vermiformis in surface water by using real-time PCR. Appl. Environ. Microbiol. 72, 5750-6. doi:10.1128/AEM.00085-06

Lehtola, M.J., Juhna, T., Miettinen, I.T., Vartiainen, T., Martikainen, P.J., 2004. Formation of biofilms in drinking water distribution networks, a case study in two cities in Finland and Latvia. J. Ind. Microbiol. Biotechnol. 31, 489-94. doi:10.1007/s10295-004-0173-2

Leoni, E., Legnani, P.., Bucci Sabattini, M.., Righi, F., 2001. Prevalence of legionella spp. In swimming pool environment, Water Research. doi:10.1016/S0043-1354(01)00075-6

Lipphaus, P., Hammes, F., Kötzsch, S., Green, J., Gillespie, S., Nocker, A., 2014. Microbiological tap water profile of a medium-sized building and effect of water stagnation. Environ. Technol. 35, 620-628. doi:10.1080/09593330.2013.839748

Liu, G., Bakker, G.L., Li, S., Vreeburg, J.H., Verberk, J.Q., Medema, G.J., Liu, W.T., Van Dijk, J.C., 
2014. Pyrosequencing reveals bacterial communities in unchlorinated drinking water distribution system: an integral study of bulk water, suspended solids, loose deposits, and pipe wall biofilm. Env. Sci Technol 48, 5467-5476. doi:10.1021/es5009467

McMurdie, P.J., Holmes, S., 2013. phyloseq: an R package for reproducible interactive analysis and graphics of microbiome census data. PLoS One 8, e61217. doi:10.1371/journal.pone.0061217

Meier, T., Bendinger, B., 2016. Survival of pathogens in drinking water plumbing systems: impact factors and sanitation options. Water Sci. Technol. Water Supply ws2016040. doi:10.2166/ws.2016.040

Nazarian, E.J., Bopp, D.J., Saylors, A., Limberger, R.J., Musser, K.A., 2008. Design and implementation of a protocol for the detection of Legionella in clinical and environmental samples. Diagn. Microbiol. Infect. Dis. 62, 125-132. doi:10.1016/j.diagmicrobio.2008.05.004

Oksanen, J., Blanchet, F.G., Kindt, R., P. Legendre, P., Minchin, P.R., O’Hara, R.B., Simpson, G.L., Solymos, P., Henry, H., Stevens, H., Wagner, H., 2013. vegan: Community Ecology Package [WWW Document]. R Packag. http//cran.r-project.org/web/packages/vegan/index. html.

Prest, E.I., Hammes, F., Kötzsch, S., van Loosdrecht, M.C.M., Vrouwenvelder, J.S., 2013. Monitoring microbiological changes in drinking water systems using a fast and reproducible flow cytometric method. Water Res. 47, 7131-42. doi:10.1016/j.watres.2013.07.051

Prest, E.I., Hammes, F., van Loosdrecht, M.C.M., Vrouwenvelder, J.S., 2016. Biological Stability of Drinking Water: Controlling Factors, Methods, and Challenges. Front. Microbiol. 7, 45. doi:10.3389/fmicb.2016.00045

Proctor, C.R., Gächter, M., Kötzsch, S., Rölli, F., Sigrist, R., Walser, J.-C., Hammes, F., Déziel, E., Prévost, M., 2016. Biofilms in shower hoses - choice of pipe material influences bacterial growth and communities. Environ. Sci. Water Res. Technol. 2, 670-682. doi:10.1039/C6EW00016A

Proctor, C.R., Hammes, F., 2015. Drinking water microbiology-from measurement to management. Curr. Opin. Biotechnol. 33, 87-94. doi:10.1016/j.copbio.2014.12.014 
Monsieurs, P., Hammes, F., Boon, N., 2016. Absolute quantification of microbial taxon abundances. ISME J. doi:10.1038/ismej.2016.117

Rhoads, W.J., Pruden, A., Edwards, M.A., 2016. Convective Mixing in Distal Pipes Exacerbates Legionella pneumophila Growth in Hot Water Plumbing. Pathog. (Basel, Switzerland) 5. doi:10.3390/pathogens5010029

Rivière, D., Szczebara, F.M., Berjeaud, J.-M., Frère, J., Héchard, Y., 2006. Development of a real-

Rudi, K., Tannaes, T., Vatn, M., 2009. Temporal and spatial diversity of the tap water microbiota in a Norwegian hospital. Appl. Environ. Microbiol. 75, 7855-7. doi:10.1128/AEM.01174-09

Schoen, M.E., Ashbolt, N.J., 2011. An in-premise model for Legionella exposure during showering events. Water Res 45, 5826-5836. doi:10.1016/j.watres.2011.08.031

Skjevrak, I., Due, A., Gjerstad, K.O., Herikstad, H., 2003. Volatile organic components migrating from plastic pipes (HDPE, PEX and PVC) into drinking water. Water Res. 37, 1912-20. doi:10.1016/S0043-1354(02)00576-6

Soto-Giron, M.J., Rodriguez-R, L.M., Luo, C., Elk, M., Ryu, H., Hoelle, J., Santo Domingo, J.W., Konstantinidis, K.T., 2016. Biofilms on Hospital Shower Hoses: Characterization and Implications for Nosocomial Infections. Appl. Environ. Microbiol. 82, 2872-83. doi:10.1128/AEM.03529-15

Urbieta, M.S., González-Toril, E., Bazán, Á.A., Giaveno, M.A., Donati, E., 2015. Comparison of the microbial communities of hot springs waters and the microbial biofilms in the acidic geothermal area of Copahue (Neuquén, Argentina). Extremophiles 19, 437-450. doi:10.1007/s00792-015-0729-2

van der Kooij, D., Bakker, G.L., Italiaander, R., Veenendaal, H.R., Wullings, B.A., 2017. Biofilm Composition and Threshold Concentration for Growth of Legionella pneumophila on Surfaces Exposed to Flowing Warm Tap Water without Disinfectant. Appl. Environ. Microbiol. 83, AEM.02737-16. doi:10.1128/AEM.02737-16

Vedler, E., Heinaru, E., Jutkina, J., Viggor, S., Koressaar, T., Remm, M., Heinaru, A., 2013. Limnobacter spp. as newly detected phenol-degraders among Baltic Sea surface water 
bacteria characterised by comparative analysis of catabolic genes. Syst. Appl. Microbiol. 36, 525-532. doi:10.1016/j.syapm.2013.07.004

Wang, H., Bédard, E., Prévost, M., Camper, A.K., Hill, V.R., Pruden, A., 2017. Methodological approaches for monitoring opportunistic pathogens in premise plumbing: A review. Water Res. 117, 68-86. doi:10.1016/j.watres.2017.03.046

Wang, H., Edwards, M., Falkinham, J.O., Pruden, A., 2012. Molecular survey of the occurrence of Legionella spp., Mycobacterium spp., Pseudomonas aeruginosa, and amoeba hosts in two chloraminated drinking water distribution systems. Appl. Environ. Microbiol. 78, 6285-94. doi:10.1128/AEM.01492-12

Wen, G., Kötzsch, S., Vital, M., Egli, T., Ma, J., 2015. BioMig-A Method to Evaluate the Potential Release of Compounds from and the Formation of Biofilms on Polymeric Materials in Contact with Drinking Water. Environ. Sci. Technol. 49, 11659-69. doi:10.1021/acs.est.5b02539

Wilton, S., Cousins, D., 1992. Detection and identification of multiple mycobacterial pathogens by DNA amplification in a single tube. PCR Methods Appl. 1, 269-73.

Wingender, J., Flemming, H.-C., 2004. Contamination potential of drinking water distribution network biofilms. Water Sci. Technol. 49.

Zhang, Y., Lin, Y.-P., 2015. Leaching of lead from new unplasticized polyvinyl chloride (UPVC) pipes into drinking water. Environ. Sci. Pollut. Res. 22, 8405-8411. doi:10.1007/s11356-014$3999-9$ 

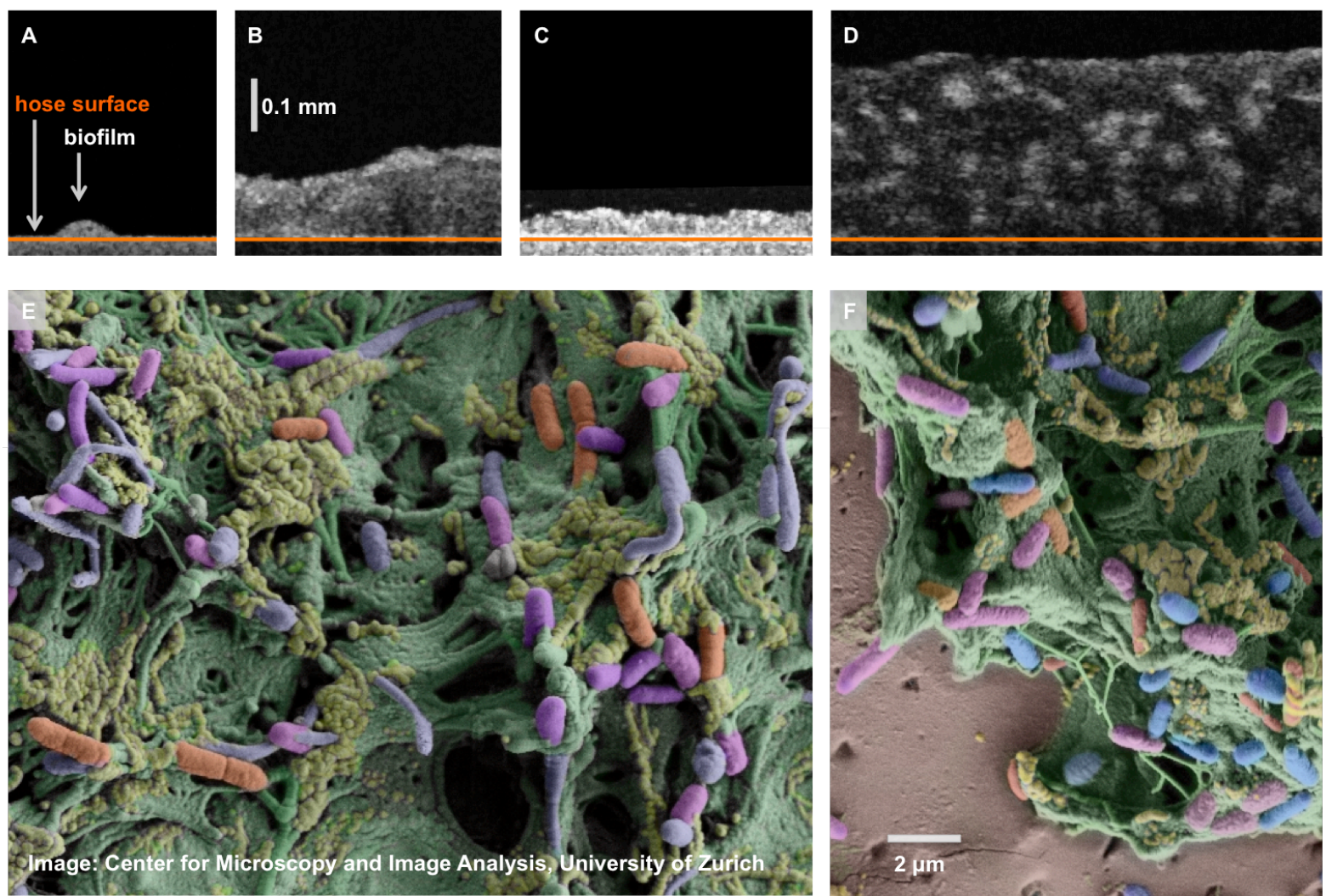

797 Figure 1: Imaging of shower hose biofilms. Top: Optical coherence tomography of biofilms with

All OCT images are on the same scale. Bottom: Scanning electron microscopy of thick biofilms

800 from a Swiss shower hose with EPS matrix (green), and cellular (orange, purple, blue) components.

801 Images $(E)$ and $(F)$ are from the same hose. In (F) hose surface (dusty rose, left bottom) together 802 with biofilm matrix (right top). SEM images were colored artificially to highlight various biofilm ele803 ments. Original images can be found in Figure S2. 

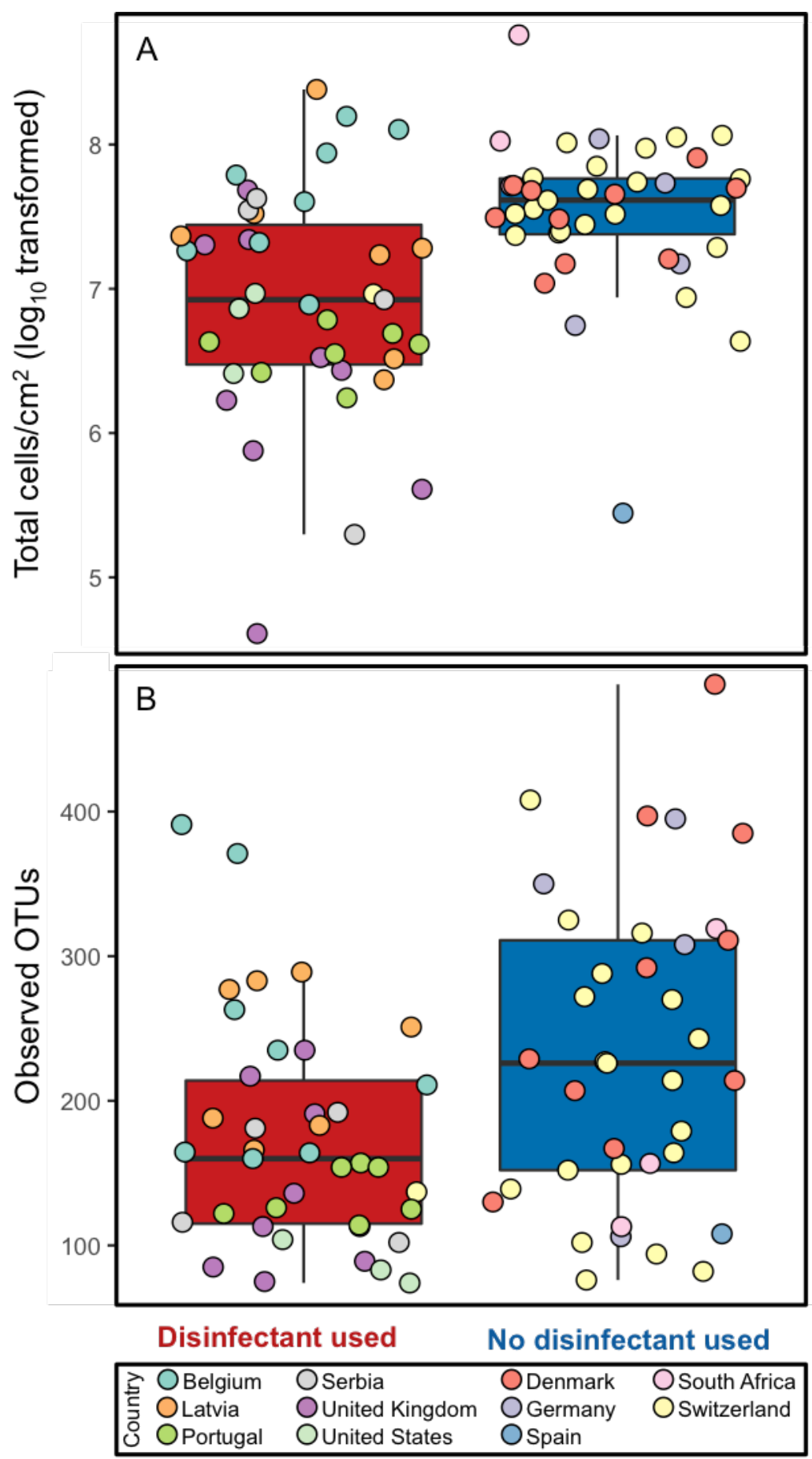

806 Figure 2: Biofilm total cell concentration (Biofilm TCC) (A) and number of observed operational 807 taxonomical units (OTUs) (B) of shower hoses, grouped by use of disinfectant (red) or lack of disin808 fectant (blue). Individual sample values are shown as dots, colored by country of sample origin. 809 Box and whisker plots represent median and quartile values for each measure. 



\begin{tabular}{|lll|}
\hline $\begin{array}{l}\text { During global survey } \\
\text { During follow-up }\end{array}$ & of & $\begin{array}{l}\text { in operation for shorter period } \\
\text { during survey than follow-up }\end{array}$ \\
Shared in both & \& $~$ & total value if beyond axis \\
\hline
\end{tabular}

811 Figure 3: Paired comparison of total cell counts (A), iron (B), lead (C), and copper (D) between 812 global survey (red) and controlled experiment (blue), with overlapping concentrations in purple.

813 Shower hoses are arranged in order of descending cell concentration in global survey, with the ex-

814 ception of three hoses on the right. These hoses were known to be in operation $<1.5$ years prior to 815 the global survey, i.e., less than in the controlled experiment, and are indicated with a symbol. 816 Concentrations beyond the reasonable axes are labeled with real values due to wide variations. 

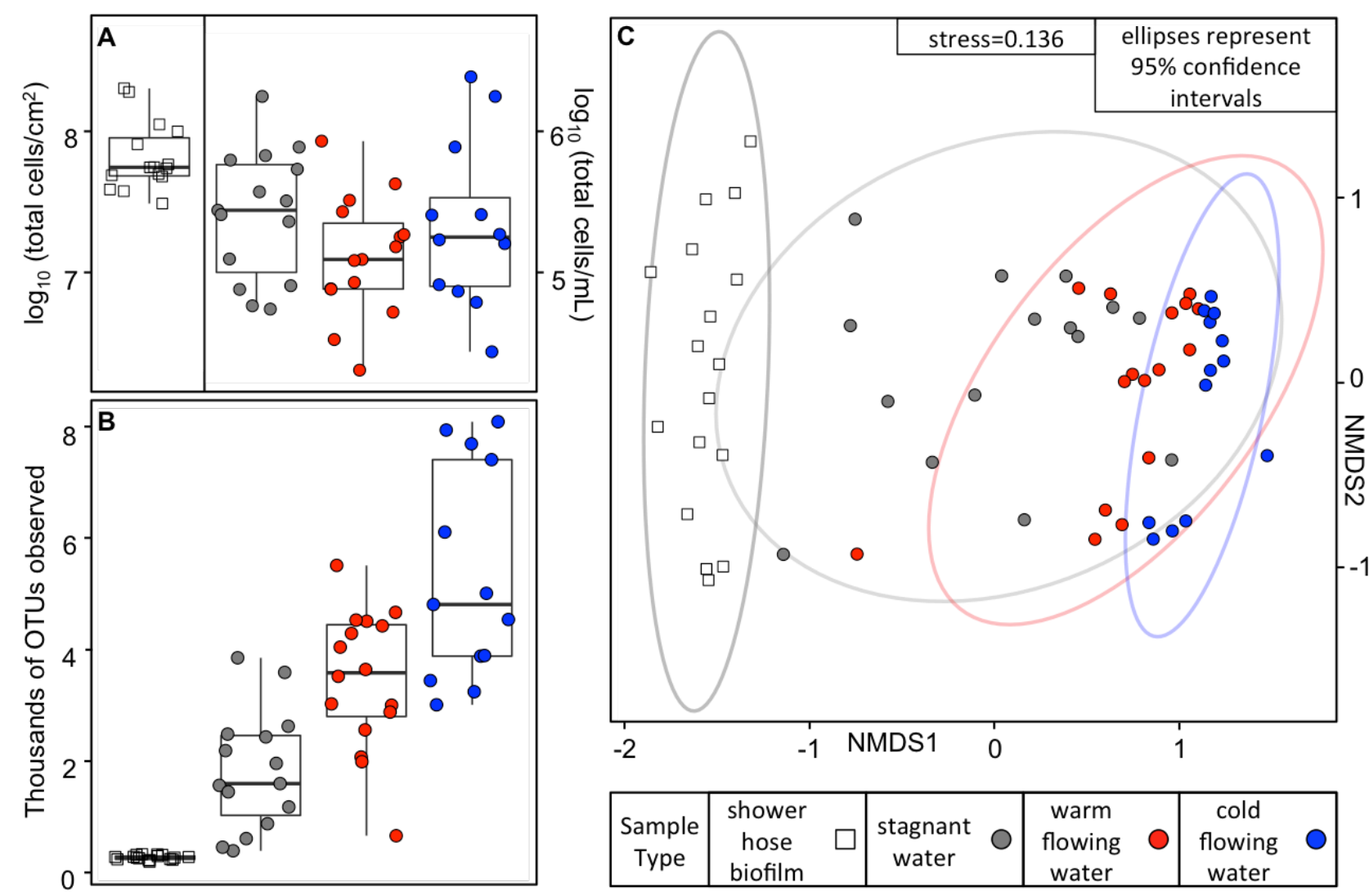

818 Figure 4: (A) Total cell concentration (TCC) (B) Diversity (observed OTUs) and (C) NMDS repre-

819 senting Bray-Curtis dissimilarities for biofilm and each group of collected water in the follow-up 820 study. For TCC, biofilm TCC is on the left axis and water TCC is on the right axis. Stagnant water 821 was collected from the shower hose after a minimum 8 hour stagnation. Warm water was collected 822 at "typical shower temperature" after 5 minutes of flow. Cold water was collected from the kitchen 823 tap after 5 minutes of flow. For total cells, $\mathrm{N}=15$ except for cold water, where $\mathrm{N}=12$, because sev824 eral hoses shared nearest cold-water sources. For sequencing data, $\mathrm{N}$ also includes triplicate 825 measurements for 1 biofilm, and duplicate samples for one warm water and one cold water. 


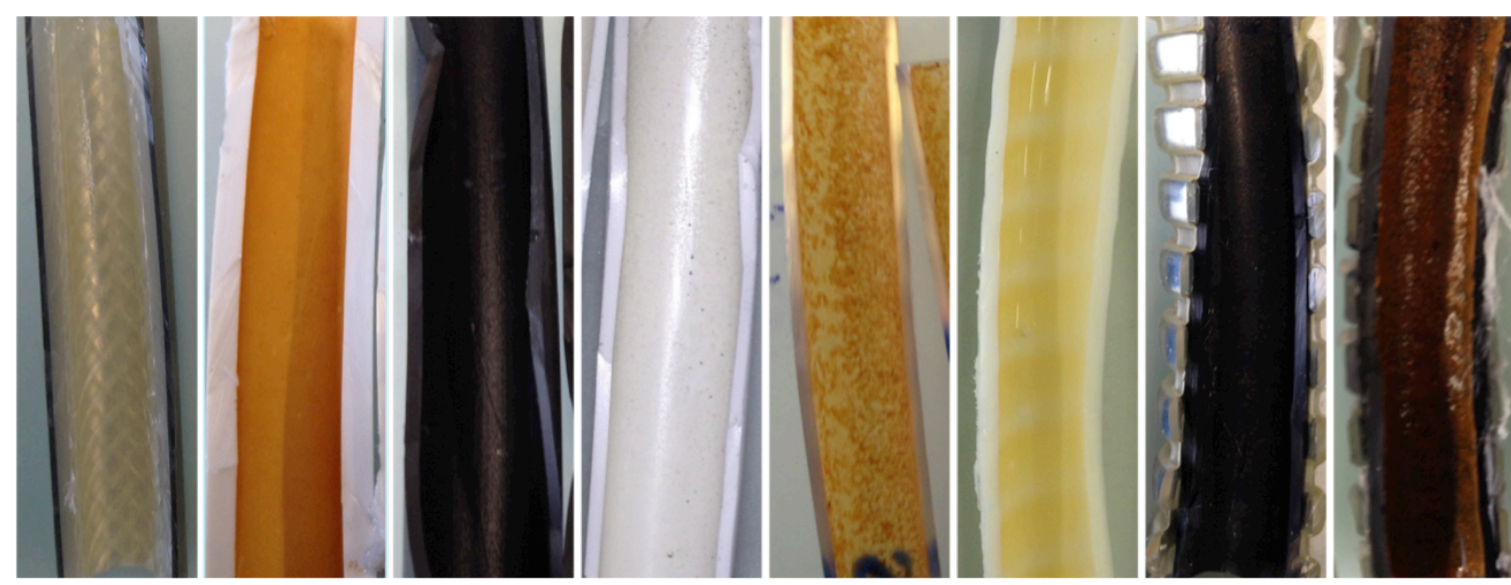

828 Figure 5: Photos of shower hoses cut open to reveal biofilms. The hoses had diverse diameters 829 and materials, and biofilms on the hoses had different color, coverage, and texture. 

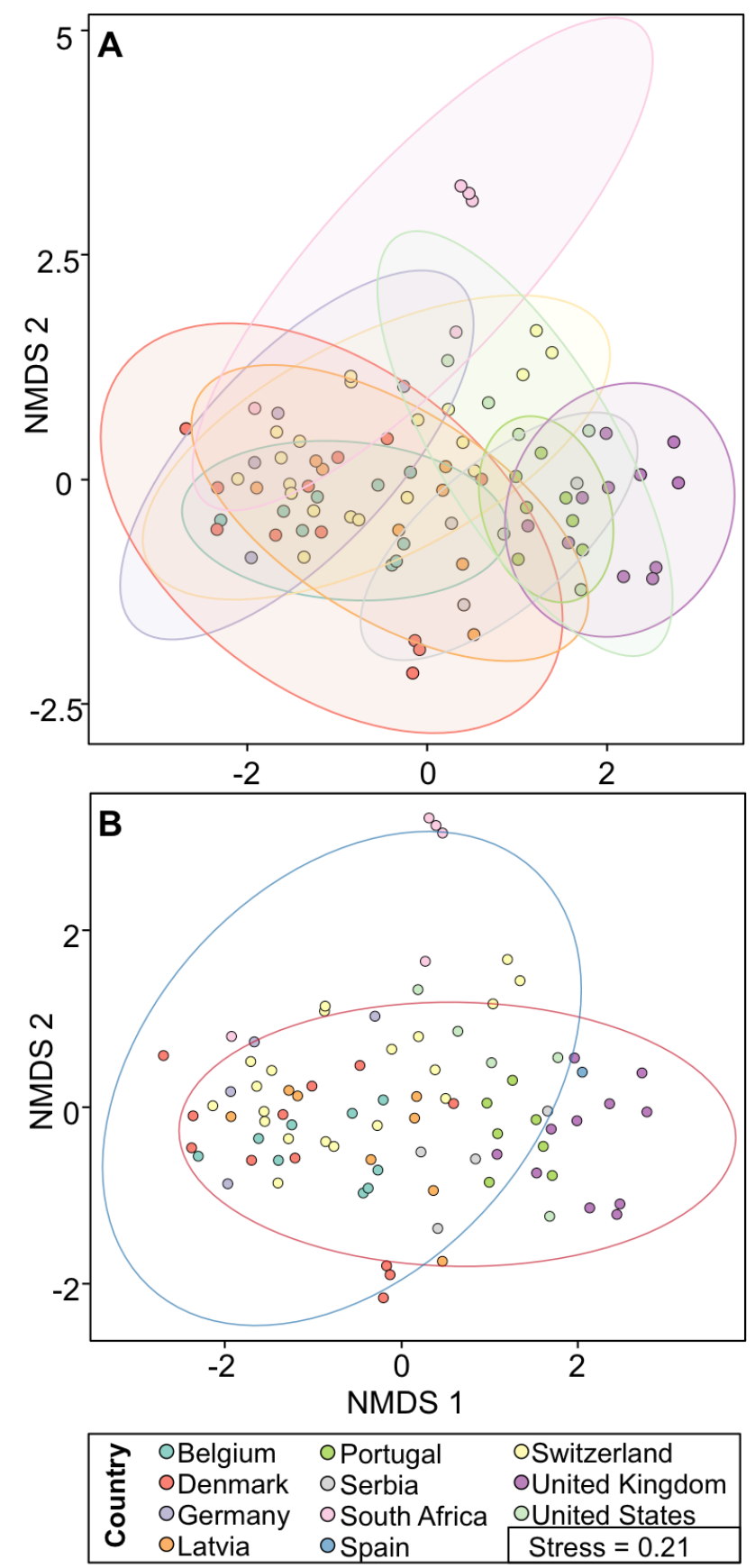

832 Figure 6: Non-metric multi-dimensional scaling (NMDS) representing Bray-Curtis dissimilarities of 833 biofilm microbiomes, with each point representing a microbiome measurement of a shower hose, 834 colored by country of sample origin. Each panel is the same NMDS superimposed with statistical 835 analyses. Colored ellipses representing 95\% confidence intervals for (A) country, and (B) use [red] 836 or non-use [blue] of disinfectant. 


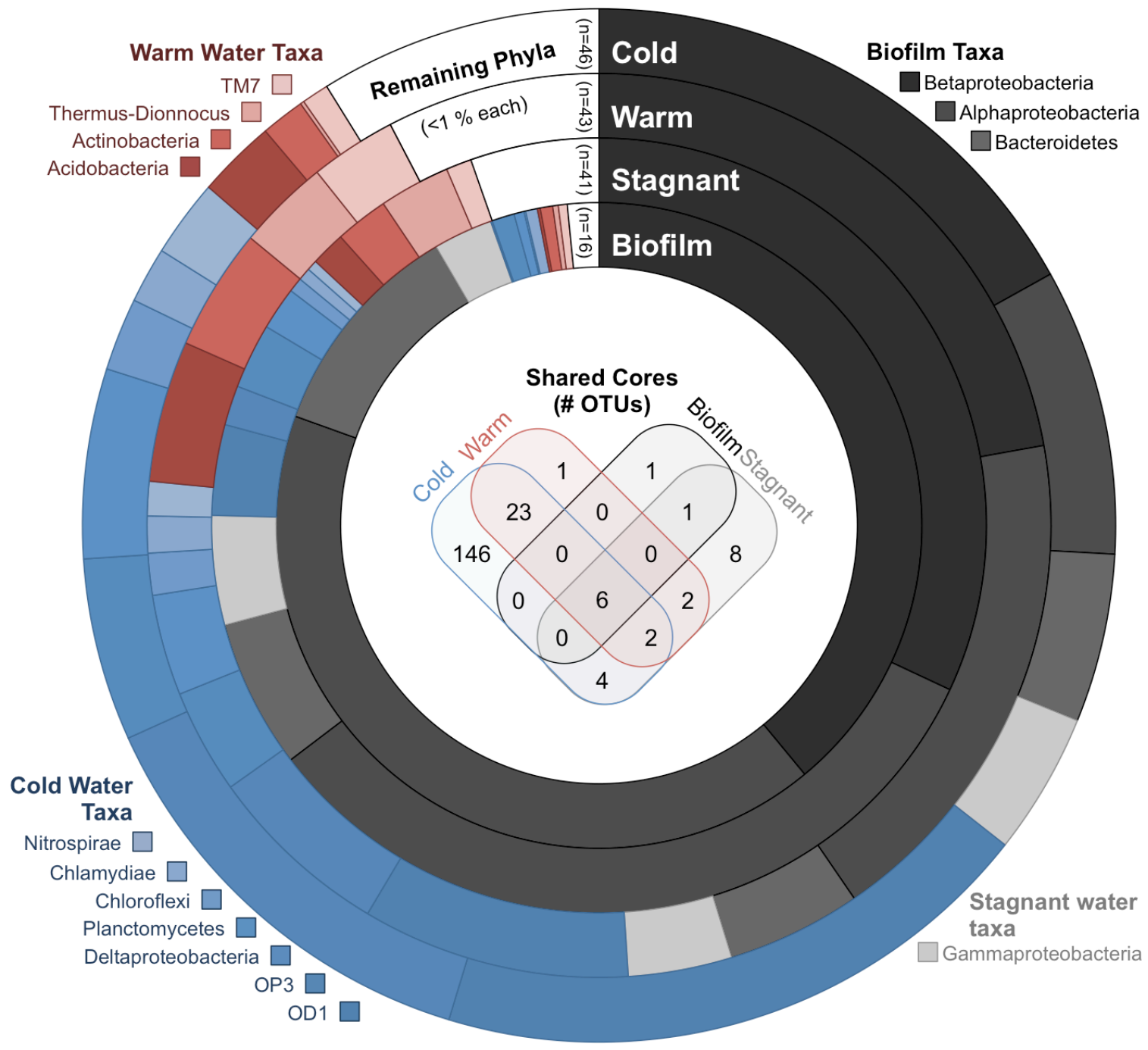

839 Figure 7: Core OTUs (center) and average relative abundance (outer rings) of Phyla (and Proteo840 bacteria-classes) by sample type (biofilm, stagnant water, warm water, and cold water) in the fol841 low-up study. The number of core OTUs was calculated as the OTUs present in all locations of 842 each type or overlapping type (e.g., 6 OTUs were common to all locations in all sample-types). 843 Each ring represents the average of 15 samples, or for cold water 12 samples due to repeat sam844 ples from single households. Phyla are colored by the phase in which they represent the highest 845 proportion - biofilm (black), stagnant (gray), cold (blue), and warm (red). These taxa are also la846 beled in the outer corners. 


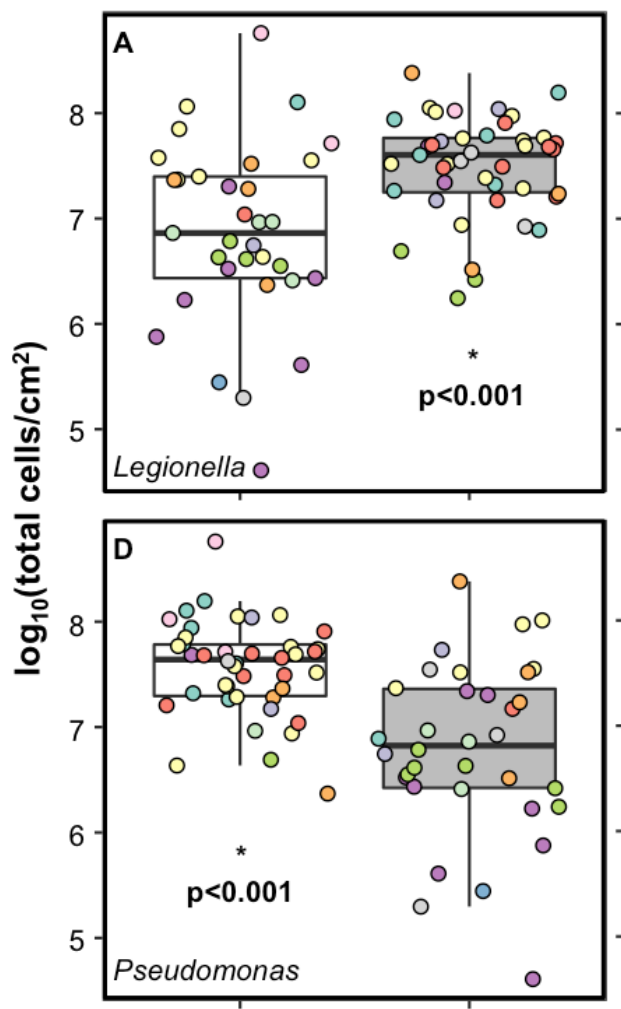

Absent
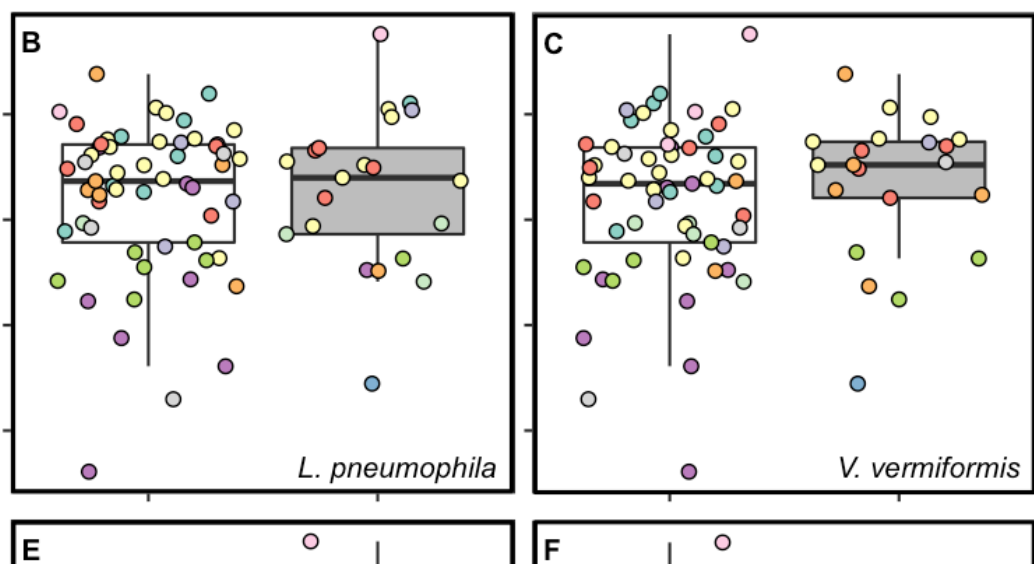

E

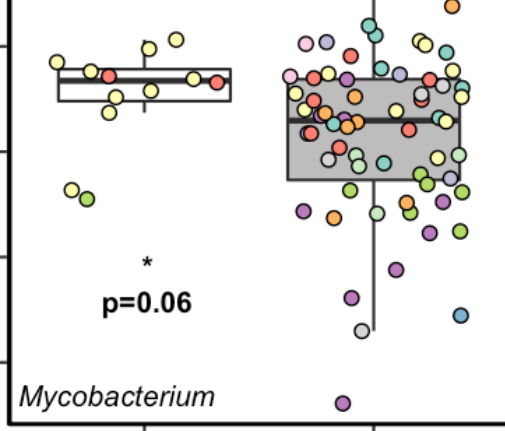

Present

OUnited Kingdom OUnited States

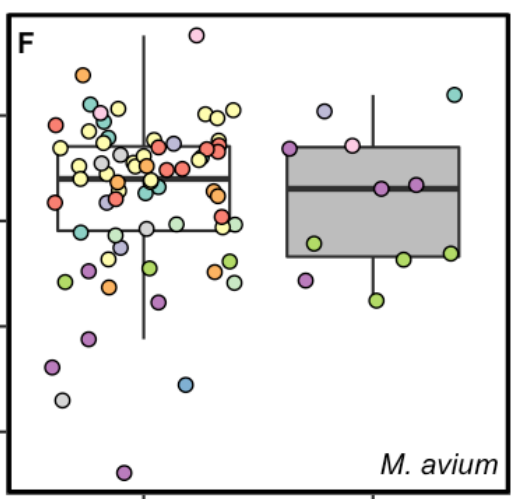

Absent

Present indicates higher group (present vs. $\mathrm{p}=\mathbf{0 . 0 1}$ absent) and Kruskal-Wallis $p$-value

\begin{tabular}{|lllll|}
\hline \multirow{2}{*}{ Country } & OBelgium & OLatvia & OSouth Africa & OUnited Kingdom \\
& ODenmark & OPortugal & OSpain & OUnited States \\
OGermany & OSerbia & OSwitzerland & \\
\hline
\end{tabular}

850 Figure 8: Total cell counts ( $\log _{10}$ transformed) grouped by absence (white, left) or presence (shad851 ed, right) of potential opportunistic pathogens, as measured by detection of genus with amplicon sequencing $(A, D, E)$, or detection of a specific opportunistic pathogen with qPCR $(B, C, F)$. Three opportunistic pathogens containing genera- Legionella (A), Pseudomonas (D), and Mycobacterium 854 (E), two opportunistic pathogens - L. pneumophila (B), and M. avium (F), and one amoeba known 855 to host L. pneumophila - V. vermiformis (C) were analyzed. Individual sample values are shown as 856 dots, colored by country of sample origin. Box and whisker plots represent median and quartile 857 values for each measure. $\left({ }^{*}\right)$ and $p$-values are displayed under box plots of groups with higher average cell concentration (Kruskal-Wallis). 
Biofilms in Shower Hoses

864

Table S1: News items concerning Legionella pneumophila, all published in the first half of 2017. 866

Table S2: Elemental Analysis Method Details

868

Table S3: qPCR method details

870

Table S4: Details for Illumina sequencing

Table S5: Details for Illumina sequencing data processing

Figure S1: Optical Coherence Tomagraphy (OCT) images of biofilms from 2 hoses from Belgium

(Hose 1) and Switzerland (Hose 2). All are on an equal scale. A and B are from opposite ends of the same hose (Hose 1). C, E, and F are from one $5 \mathrm{~cm}$ piece on one end of a hose, while $D$ is from the opposite end of the same hose (Hose 2).

Figure S2: Original black and white images (zoomed out) of biofilms on shower hoses, corresponding to Figure 1E (top) and $1 \mathrm{E}$ (bottom). In Figure 1, only particular sections were shown in order to focus attention. Color was also added artificially to highlight key biofilm elements.

Figure S3: Correlation between various measures of biofilm concentration. All scatter-plot points represent values for individual shower hose samples, colored by country of sample origin. Some factors (Total cells, intact cells, ATP, and 16S qPCR gc) are transformed as indicated due to the wide spread of values. 
Table S6: Water quality and use patterns for 15 samples in follow-up study

Table S7: Correlation values between use patterns and calculated weekly doses and biofilm concentration. Calculated weekly loads were derived by multiplying the number of uses per week by water quality concentrations (nitrogen, phosphorous, magnesium, calcium or total cells in the cold flowing water, (Table S6)) and the volume inside a shower hose. For all, N=15 for the 15 biofilm samples. Uses per week alone (e.g., without multiplying by a water quality parameter) had the strongest correlation with biofilm TCC, while other water quality measurements had only moderate correlations. That is to say, no single nutrient or load was controlling the system with stronger predictive power than frequency of alone. It could be either a combination of nutrients/cells or some other aspect of frequency of use that controls the biofilm TCC.

Figure S4: Photo from outside of a shower hose, with metal partially removed (left), and the inside of a shower hose with a particularly red/orange biofilm (right). On the left, biofilm formed yellow spots, resembling bacterial colonies on agar. On the right, the biofilm had a rough texture and deep red/brown/orange color.

Figure S5: Concentrations of metals (lead, iron, copper, calcium, and magnesium) and biofilm total cell concentration (biofilm TCC), with their correlations. Points represent individual hoses, colored by country. None of the metals correlated well with biofilm TCC. There were many non-detects for lead, iron and copper, but when present, there tended to be positive relationships between these metals - i.e., these metals precipitated together in biofilms. Calcium and magnesium were present in all biofilms, and had a positive relationship with each other. While the first three metals likely originate from up-stream pipes in the distribution system, calcium and magnesium likely originate 913 from hardness in the water.

Figure S6: Correlational analyses between relative abundance of genera (sum of all OTUs identified within that genera) and biofilm total cell concentration (TCC) (log10 transformed). Points represent individual hoses, colored by country. Spearman rank correlations noted for correlations with 
918 biofilm TCC, with $\left(^{*}\right)$ indicating $p<0.001$. These are the three most significant positive and negative 919 correlations from the top 10 most abundant genera, but these do not necessarily represent the 920 strongest correlations. For example, a significant positive correlation was found between Legionel921 la and biofilm TCC (Spearman's $\rho=0.36, p<0.001$ ). This analysis focused on the top 10 most 922 abundant genera because more frequent non-detects with less abundant OTUs likely affected re923 sults strongly. Notably, two genera from within the same family (Sphingomonas and Sphingobium) 924 were both amongst the top 10 most abundant genera, but had opposite correlations.

926 Figure S7: NMDS representing Bray-Curtis dissimilarities between samples in follow-up experi927 ment. Samples consist of 15 biofilms, and matching stagnant water, warm running water, and cold 928 running water. Ellipses represent $95 \%$ confidence intervals for each household. These ellipses are 929 generally narrow across an NMDS2 range, but extend widely through NMDS1 to capture all sam930 ple types. Household explained $41 \%$ of microbiome variation (Adonis). Thus, while there are simi931 larities between sample types (symbol type and color), there are some strong similarities in a 932 household. This could, for example, be due to drift into the household (cold flowing water) selecting 933 downstream microbiomes.

935 Table S8: Products available for addressing biofilms in shower hoses, including quarterly replace936 ment systems and single-use shower hoses. 